Journal of Advanced Research in Fluid Mechanics and Thermal Sciences

Journal homepage: www.akademiabaru.com/arfmts.html ISSN: 2289-7879

\title{
Potential of Micro-Vortex Generators in Enhancing the Quality of Flow in a Hypersonic Inlet-Isolator
}

\author{
Azam Che Idris ${ }^{1}$, Mohd Rashdan Saad ${ }^{2,}$, Konstantinos Kontis ${ }^{3}$ \\ Faculty of Integrated Technologies, Universiti Brunei Darussalam, BE1410, Brunei Darussalam \\ Department of Mechanical Engineering, Faculty of Engineering, Universiti Pertahanan Nasional Malaysia, Kem Perdana Sungai Besi, Kuala \\ Lumpur 57000, Malaysia \\ 3 Mechan Chair of Engineering, Aerospace Sciences Division, James Watt School of Engineering, University of Glasgow, G12 8QQ, Scotland, \\ United Kingdom
}

\section{ARTICLE INFO}

\section{Article history:}

Received 19 April 2020

Received in revised form 29 July 2020

Accepted 2 August 2020

Available online 29 October 2020

\section{Keywords:}

shock wave-boundary layer interaction;

micro-vortex generator; flow separation

\section{ABSTRACT}

The rush to be the first to demonstrate a practical hypersonic cruise missile has never been more frantic among the world's superpowers, especially since China and India have also announced their own programme. The main hurdle for safe hypersonic flight is the severe shock wave-boundary layer interaction (SWBLI) that could induce flow separation. The separation could lead to inlet unstart and also structural damage at the flow re-attachment point. The simplest method to control these phenomena is by using passive flow control devices such as micro-vortex generator (MVG). The MVG is typically sized in the range of sub-boundary layer and the vortex generated can induce an early transition to turbulence thus avoiding or reducing the impact of flow separation. Many studies have been published with regard to MVG, but most were done in low supersonic speed and not in the hypersonic flow regime. In the current study, the MVG array was placed strategically at various locations on a hypersonic inlet-isolator representative geometry. The MVG has been proven to be very effective in eliminating or reducing the size of flow separation thus reducing the associated peak pressure at the re-attachment point.

\section{Introduction}

There has been a frenzied rush in the defence sector to develop cruise missiles capable of flying at hypersonic speed. The United States, Russia, China and India has been teasing the world with announcements of their future hypersonic missile programs. Missiles flying at hypersonic speed must rely on the supersonic combustion ramjet (scramjet) technology to compress and heat air for propulsion [1]. The scramjet engine's ability to regulate the quality of airflow going into the combustion chamber is highly sensitive to the shape of the compression ramp and isolator sections

\footnotetext{
* Corresponding author.

E-mail address: rashdan@upnm.edu.my
}

https://doi.org/10.37934/arfmts.77.1.110 
[2]. The compression is done via series of oblique shocks placed externally and also internally. This is achieved by optimizing the intake shape for operation at the design point. However, the flow is usually subjected to the shock wave - boundary layer interactions (SWBLI) phenomenon, which can cause boundary layer separation and flow distortion going into the combustion chamber [3, 4]. In the worst-case scenario, the boundary layer separation bubble can induce inlet-unstart, where the flow is totally restricted from going into the combustion chamber thus causing total engine failure. Hence, it has become the focus of many studies in recent years to understand the shock-boundary layer interactions of the flow at the scramjet inlet/isolator section [5-12].

Recently, researchers are focusing on controlling the shock-boundary layer interactions using sub-boundary layer micro-structures in the shape of ramp or riblet [13-16]. The micro-structures are called micro-vortex generators (MVG) due to its ability to produce counter-rotating vortices which will travel downstream and reduce the impact of boundary layer separation [17-20].

The multitude of MVG related studies in supersonic intake type flow were done in low supersonic speed. For example, Zhu et al., recently reported their work on visualization on the structures of supersonic flow over backward-facing step with vortex generators [21]. Their flow speed was limited to Mach 3.4 and their measurements were limited to background oriented schlieren (BOS) and nanotracer laser scattering only. In another paper, Qinghu et al., applied nano-tracer laser scattering to investigate the effect of micro-ramps vortex generator on a double-ramp geometry in Mach 3 flow [22]. In 2019, Kaushik reported the effectiveness of MVG in reducing SWBLI effect on a Mach 2.2 intake. His MVG was placed on the intake's external compression ramp just a small distance upstream of the throat section [23]. Verma and Manisankar also demonstrated the usefulness of vane-type vortex generators in reducing the impact of Mach reflection-induced interaction inside an intake with an internal flow of Mach 2.05 [24]. From the literature, a significant gap existed in the domain of MVG interaction with a separation bubble in hypersonic speed flow. Most studies focused only on low supersonic flow.

Hence, it is our objective to study MVG effectiveness in mitigating flow separation problem in the hypersonic flow. The experimental campaign is to be divided into three parts. For the first part, an array of MVG will be placed on the compression ramp to see its effect in reducing the separation at the compression corner. For the second part, an array of MVG will be placed on upstream of the isolator section to observe its impact on the flow quality inside the scramjet isolator. For the third and final part, a simplified contracting rectangular isolator will be equipped with a single MVG in a Mach 5 flow in order to visualize MVG interactions with a separation bubble.

\section{Methodology}

\subsection{Mach 5 Hypersonic Wind Tunnel and Scramjet Model}

The experiments were conducted in a hypersonic speed capable wind tunnel in the University of Manchester (see Figure 1). It is of blow-down type and can produce flow with unit Reynolds number of $13.2 \times 106 \mathrm{~m}^{-1}$ at stagnation pressure and temperature of 6.5 bar and $375 \mathrm{~K}$. The flow duration can achieve up to 10 seconds depending on the flow settings, thus allowing a realistic amount of time for boundary layer growth. The boundary layer for model tested in this wind tunnel can be considered laminar unless tripped such as reported by references [13] and [14].

The high-speed flow is sourced from the pressure tank with 16 bar operating pressure. The driven air is heated using a direct-current electric resistive heater with $24 \mathrm{~kW}$ of power. The nozzle can be changed to provide a Mach number between 4.0 to 6.0. In the current experiment, only Mach 5 nozzle was utilized. The test section has windows on the top and sides to allow access for opticalbased measurement and inspection. 
The dimension of the scramjet model used in the first and second part of the experiment follows the scramjet geometry reported in Idris et al., [10]. The MVG arrays for the first and second part of the experiments were manufactured to similar dimension reported by Idris et al., [16]. In the third part, the solitary MVG is sized according to the report by Saad et al., [13].

\subsection{Pressure Sensitive Paints (PSP)}

Figure 1 shows the PSP set up to measure the static pressure on the surface of our models. A specialized CCD camera was placed on top of the tunnel whilst the light sources to illuminate the paint were positioned on the side windows (see Figure 2). A 12-bit LaVision Imager Intense CCD camera was used as the main photon receptor. It was set with an exposure time of $7.5 \mathrm{~ms}$ and 10 frames per second capturing ability. The illumination was supplied by two ultraviolet LED panels with monochromatic nature. A specialized filter was installed in front of the camera to allow photon with specific wavelengths to enter. The current experiments relied only on in-situ calibration to convert photon intensity readings into pressure. The experiments were done in the darkest possible condition to reduce unwanted photon captured from the environment background. Post-processing of the image was done using LaVision DAVIS 7.0 software.

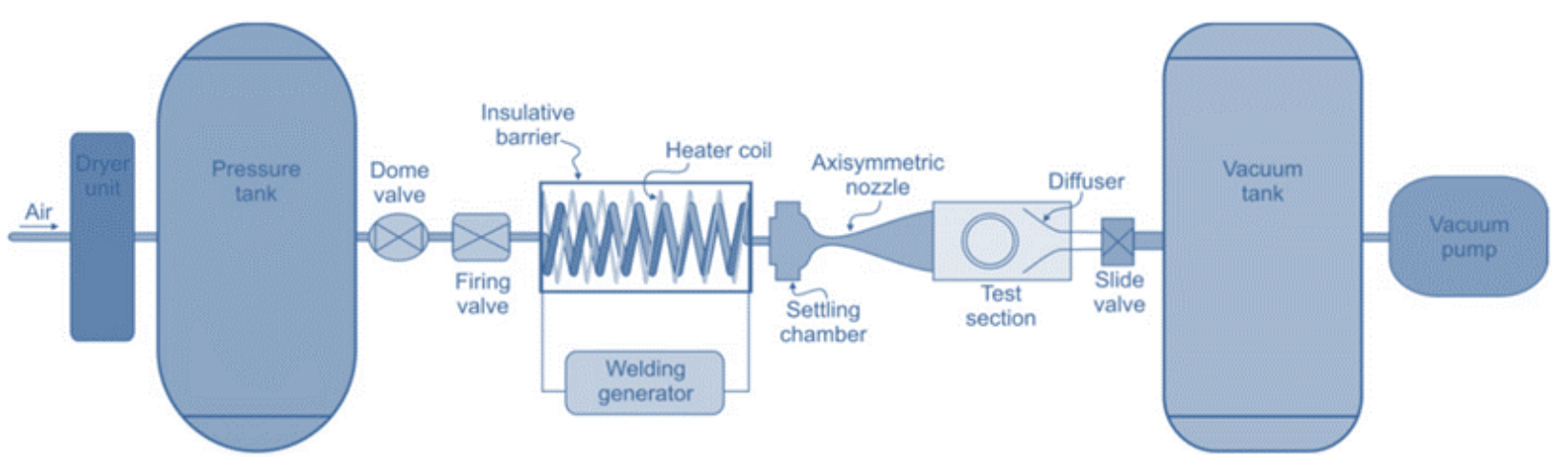

Fig. 1. Schematic of hypersonic wind tunnel used in this experimental campaign

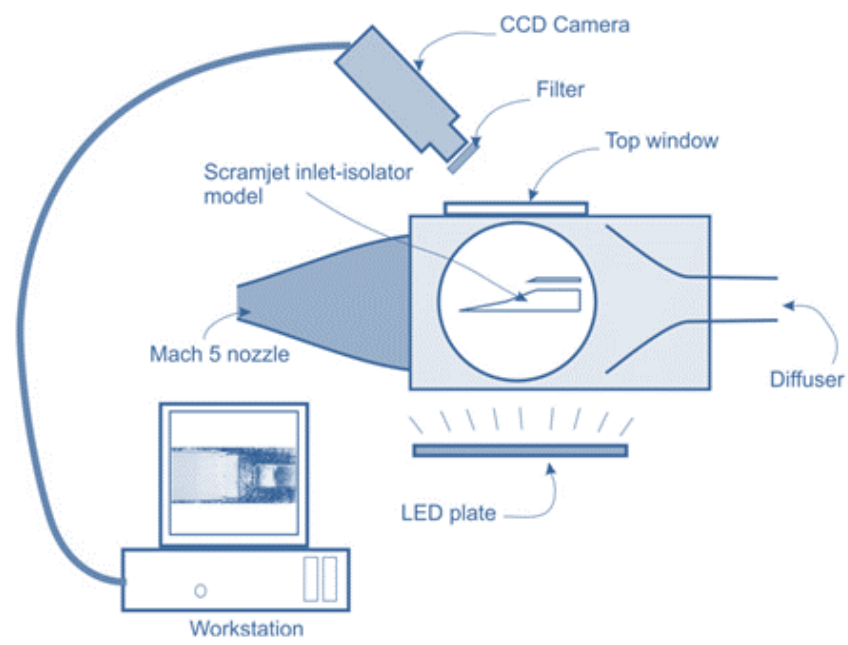

Fig. 2. Schematic of pressure sensitive paint system setup 


\subsection{Infrared Thermography}

Surface temperature readings were measured using FLIR ThermaCAM SC 3000 infrared camera. The capture rate was set to 100 frame per second (fps) in 14-bit format. The camera was placed on the top window, which is installed with germanium material for IR measurement. The models were painted black in order to achieve emissivity of 0.95 . Due to the models being made with aluminium alloy, heat transfer reading could not be inferred thus vortex formation can only be observed via the temperature increase at every two seconds interval.

\subsection{Numerical Setup}

Due to the various difficulties in performing experimental analysis in hypersonic flow, computational fluid dynamics (CFD) must be relied upon for comprehensive investigation of a scramjet engine. Typically, the hypersonic research team around the world depends on proprietary codes that were not released to the public domain as their codes are finely tuned for their own aerothermal applications. Nevertheless, it was found that ANSYS FLUENT could be utilized as a good numerical solver for investigating the scramjet intake problem as this code is robust enough for many thermal-fluid problems involving large pressure/temperature gradient [25-28]. The solver was a density-based Navier-Stokes solver with the SST k-Omega turbulence model.

There were a multitude of turbulence models to be chosen in FLUENT. However, many related literatures suggested that Menter's SST k-Omega can model flow separation in hypersonic flow without incurring high computational cost [29-33]. Nguyen et al., stated that the contribution of turbulence kinetic energy to the total energy is significant in hypersonic flows especially when separation is expected [30]. Reinartz concluded that SST k-Omega is comparable to the more computationally extensive Reynolds Stress Model (RSM) which is a five-equation model. The turbulence intensity at freestream was set to $0.5 \%$.

The grid was structured such that the $\mathrm{y}^{+}$value is less than 1 at the boundary layer regions (see Figure 3). Higher order accuracy was achieved by utilizing Second Order Spatially Accurate Upwind Scheme (SOU) with Roe's Flux-Difference Splitting. Mesh sensitivity study has been performed and we found that 52,000 cells (medium mesh) were enough to gain satisfactory fit to the experimental pressure data (see Figure 4).

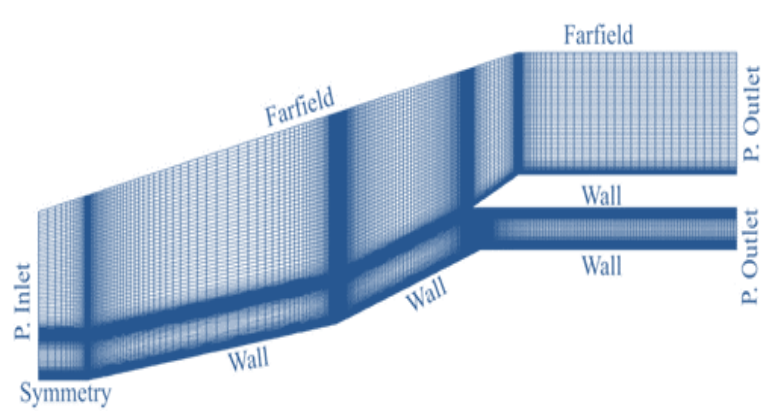

Fig. 3. Mesh used in this study

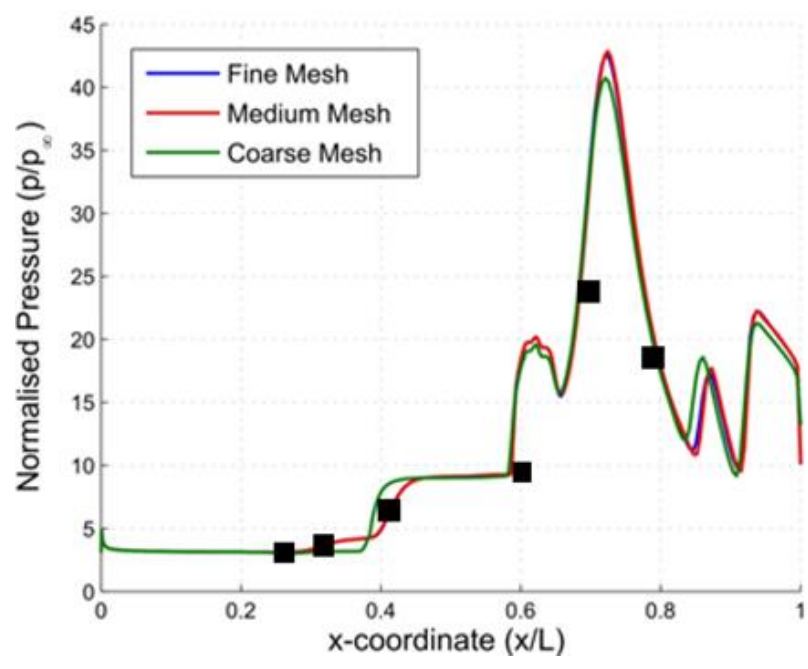

Fig. 4. Grid sensitivity study 


\section{Results and Discussion}

\subsection{Effect of MVG on The Flow Separation at Compression Corner}

An array of MVGs has been installed at a normalized distance of $x / L=0.11$ from the leading-edge of the scramjet inlet-isolator (see Figure 5). At this location, the boundary layer thickness was found to be $0.7 \mathrm{~mm}$. The array consisted of three similar MVGs placed next to each other with the half apex angle of each of $35^{\circ}$. The MVGs were prism-type with a height of $0.65 \mathrm{~mm}$ and the distance between each apex was $7 \mathrm{~mm}$. The centreline of the midapex coincided with the centreline of the scramjet inlet-isolator model.

The schlieren images in Figure 6 show that a flow separation region appeared on the case of without MVGs. The separation is identified via the appearance of a separation shock upstream of the corner location. The boundary layer was clearly visible from upstream to the separation shock.

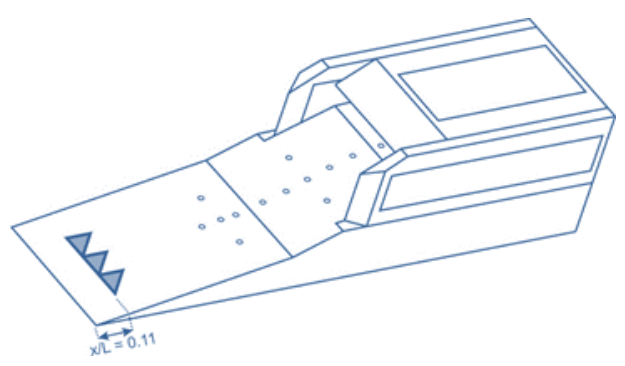

Fig. 5. MVG position on inlet-isolator

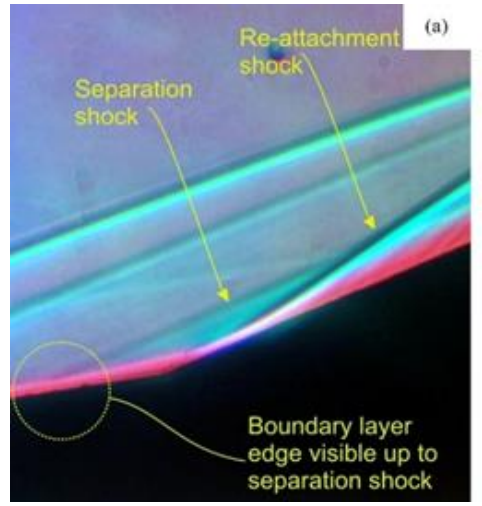

Fig. 6. Schlieren images: (a) without (b) with-MVG

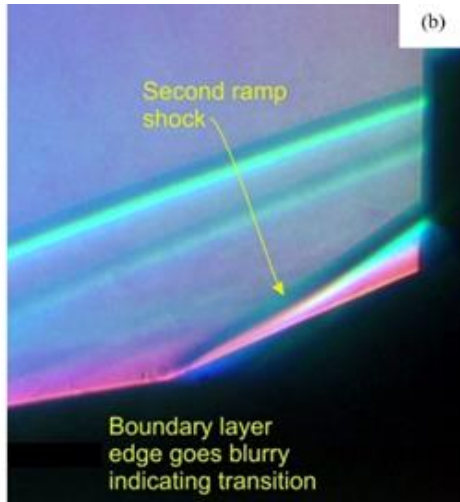

The separation was eliminated in the case with MVGs. This was caused by the induced transition from laminar to turbulent boundary layer. In the case with MVG array, the boundary layer appears blurred without a clear edge, thus indicating transition to turbulence. The transition was induced by the breakdown of vortices that emanate from each MVG as shown clearly by the infrared temperature map in Figure 7. In the figure the vortex pairs from each MVG caused slight temperature increase downstream. The streaks disappeared upstream of the compression corner thus gesturing the transition to turbulence which prevented the formation of flow separation.

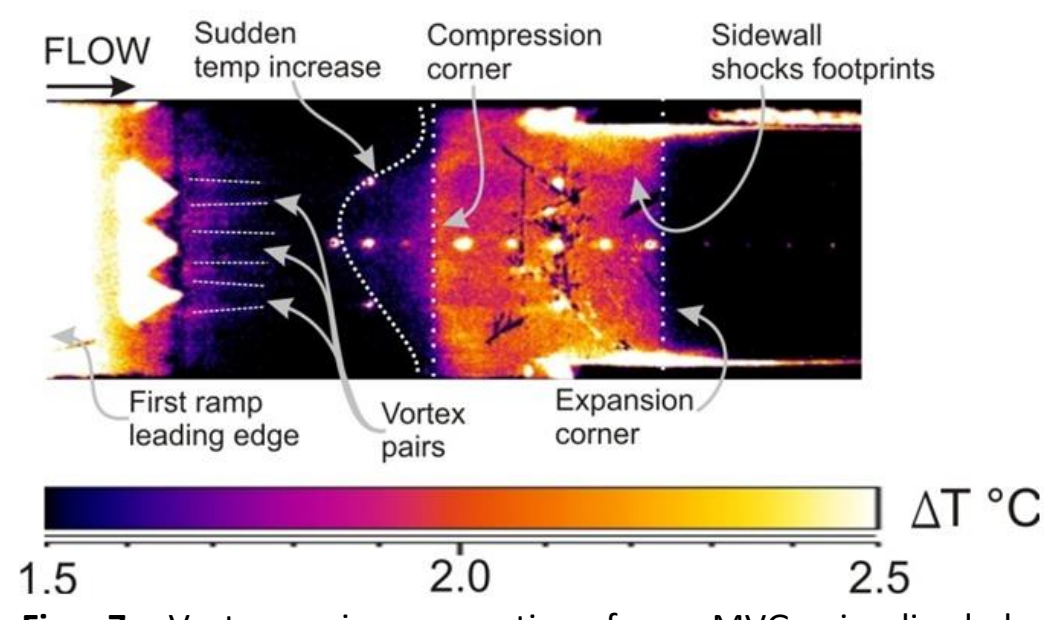

Fig. 7. Vortex pairs emanating from MVG visualized by temperature rise 


\subsection{Effect of MVG on The Supersonic Flow Inside Isolator Section}

The MVG array has been positioned at location $x / L=0.48$ (see Figure 8 ). This location was found suitable to allow enough downstream distance for boundary layer transition. The flow speed entering the isolator was estimated to be approximately Mach 3.2 and the overall flow turning needed to enter the isolator was $22 \mathrm{deg}$. In the case without the MVG array, the separation bubble was exceptionally large, with its height at almost $70 \%$ of the isolator height (refer Figure 9(a)). The shock from the shoulder separation has caused another separation on the cowl surface thus choking the flow further. The reattachment shock from the shoulder separation also caused another separation further inside the isolator section.

The case with-MVG array shows that the separation could not be eliminated but it can reduce the separation height (see figure 9(b)). The shock-waves system inside the isolator also appeared faintly visible, suggesting weaker shock consequently increasing the flow uniformity.

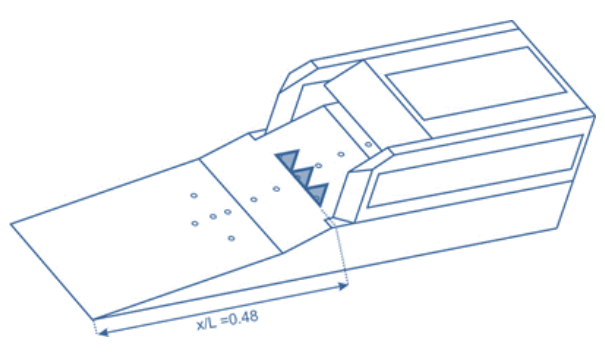

Fig. 8. MVG position on inlet-isolator

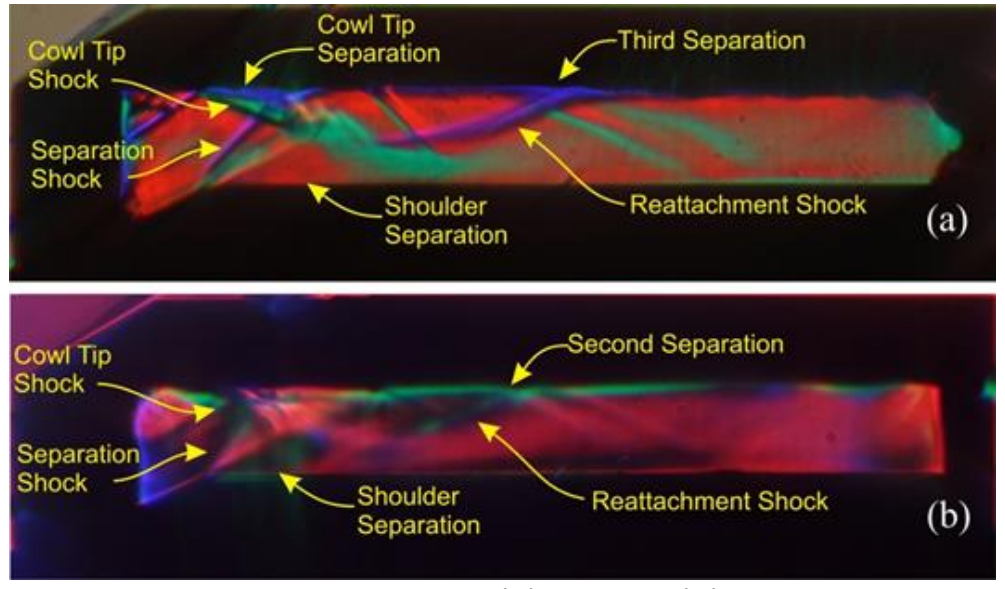

Fig. 9. Schlieren images: (a) without (b) with-MVG

The pressure readings of both cases were measured using Pressure Sensitive Paints (PSP) and Kulite pressure transducers and shown in Figure 10. It shows that for the case without MVG, the reattachment shock from the separation inside the isolator could reach almost 50 times the freestream pressure. The peak pressure was reduced by more than half for the case with-MVG. The flowfield topology is shown by the surface pressure map of the isolator in Figure 11. From this figure, we can observe that the regions close to the sidewall were not influenced by the MVG. The region affected by the MVG was confined to the width of the MVG-array, continuing downstream. Outside this region, the flow separation was severe, thus suggesting that the MVG array should be made to fully occupy the span of the inlet-isolator. 


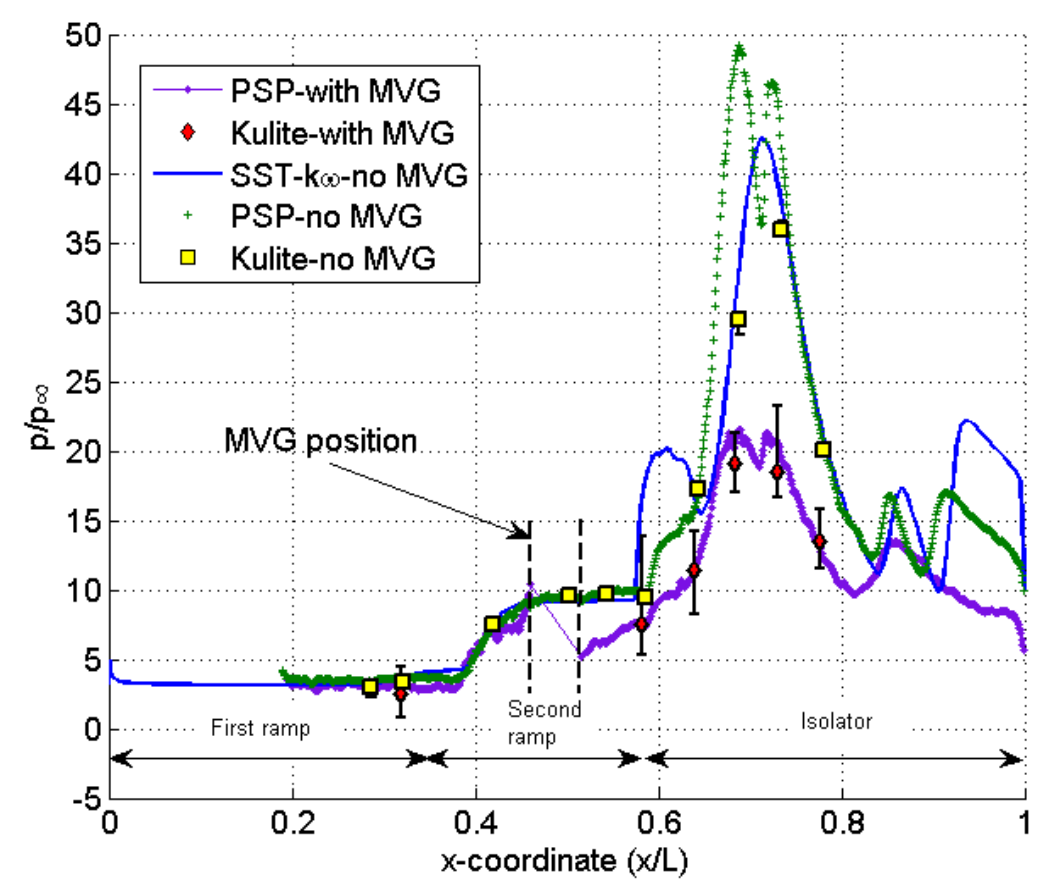

Fig. 10. Pressure on scramjet inlet-isolator
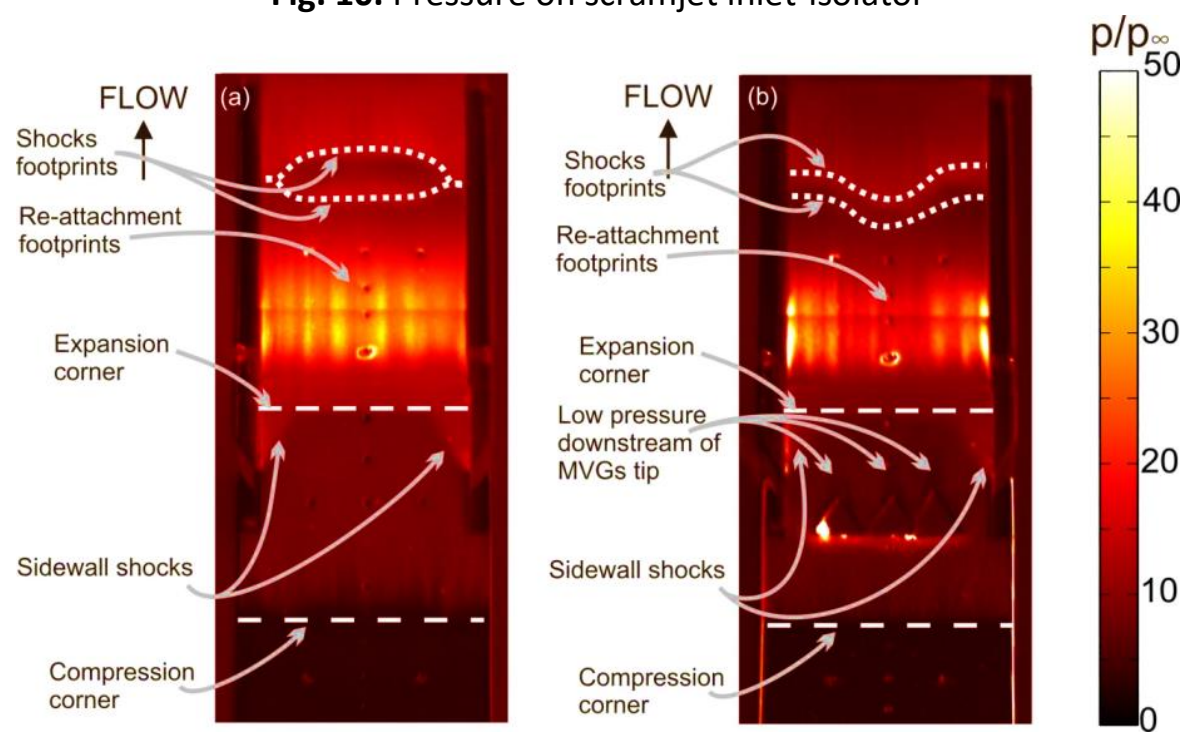

Fig. 11. Pressure map on scramjet inlet-isolator

\subsection{Effect of MVG on The Hypersonic Flow Inside Isolator Section}

To further understand the mechanism of MVG in suppressing a shock-induced separation, a simplified contracting rectangular isolator was constructed. The forced flow-turning by the cowl was replicated with a shock generator of 23-degree wedge at mid-length of the isolator (see Figure 12). The flow speed entering the isolator is Mach 5, thus the isolator was a representative of a scramjet inlet-isolator operating at the extreme Mach number of 18 and above. The strong shock generated by the shock generator has caused a large separation of approximately $30 \%$ of isolator-exit's height such as shown in the colour schlieren image (Figure 13(a)). 


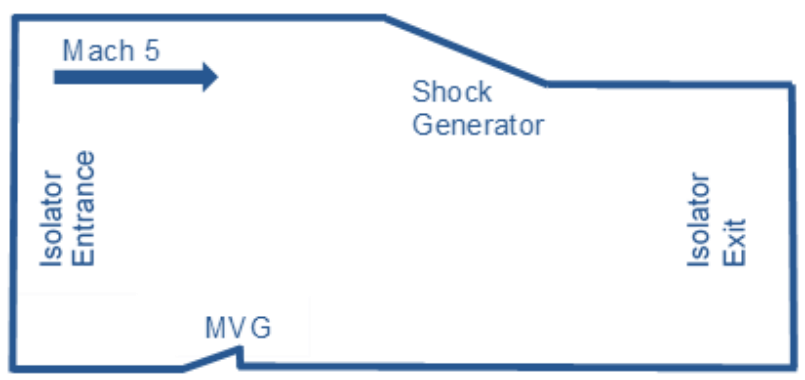

Fig. 12. Schematic of rectangular isolator

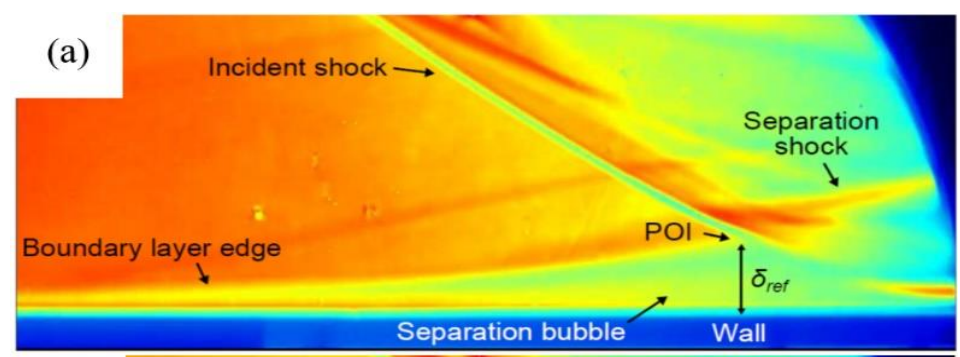

(b)

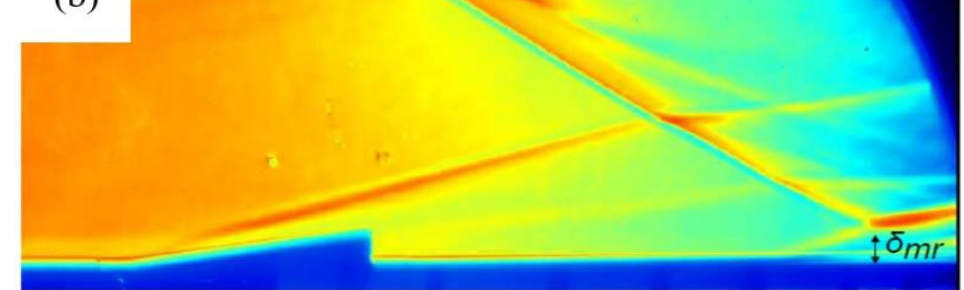

Fig. 13. Schlieren images: (a) without (b) with-MVG

In the case with-MVG, the separation has been reduced to a third of its original size (see Figure 13(b)). The reduction in separation size has caused a decline in the peak pressure at re-attachment point. This is shown clearly in the surface pressure map where the downstream region limited by the span of the MVG have a much-lowered peak pressure (see Figure 14).

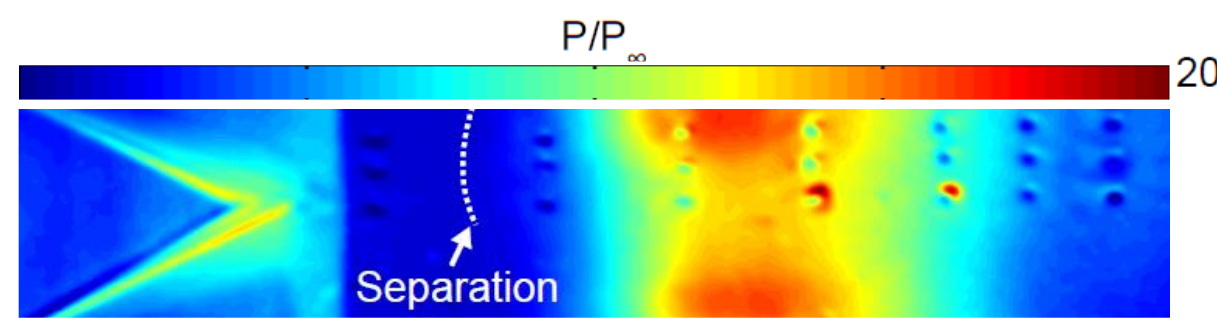

Fig. 14. Pressure map of isolator surface

\section{Conclusions}

The potential of MVG to improve quality of flow in a hypersonic intake is enormous. In the first part of the experiment, the MVG array positioned on the compression corner can induce an early transition to turbulence. The turbulence can eliminate the separation at the compression corner. In the second part, the typically large separation the inlet throat can be reduced by placing an array of MVG upstream of the shoulder. This can increase the flow uniformity in the isolator section. In the final part of the experiment, the vortex emanating from the solitary MVG can reduce the peak pressure at the separation reattachment point. 


\section{Acknowledgement}

The authors would like to thank the technical staffs of School of Mechanical Aerospace and Civil Engineering, The University of Manchester for their support during this project.

\section{References}

[1] Roberts, Kristen, and Donald Wilson. "Analysis and design of a hypersonic scramjet engine with a transition Mach number of 4.00." In 47th AIAA aerospace sciences meeting including the new horizons forum and aerospace exposition (2009): 1255. https://doi.org/10.2514/6.2009-1255

[2] Fry, Ronald S. "A century of ramjet propulsion technology evolution." Journal of propulsion and power 20, no. 1 (2004): 27-58. https://doi.org/10.2514/1.9178

[3] Delery, Jean M. "Shock wave/turbulent boundary layer interaction and its control." Progress in Aerospace Sciences 22, no. 4 (1985): 209-280. https://doi.org/10.1016/0376-0421(85)90001-6

[4] Dolling, David S. "Fifty years of shock-wave/boundary-layer interaction research: what next?." AIAA journal 39 , no. 8 (2001): 1517-1531. https://doi.org/10.2514/3.14896

[5] Gruhn, Patrick, and Ali Gülhan. "Experimental investigation of a hypersonic inlet with and without sidewall compression." Journal of Propulsion and Power 27, no. 3 (2011): 718-729. https://doi.org/10.2514/1.50347

[6] Häberle, Jürgen, and Ali Gülhan. "Investigation of two-dimensional scramjet inlet flowfield at Mach 7." Journal of Propulsion and Power 24, no. 3 (2008): 446-459. https://doi.org/10.2514/1.33545

[7] Hohn, Oliver, and Ali Gülhan. "Experimental investigation on the influence of sidewall compression on the flowfield of a scramjet inlet at Mach 7." In 17th AIAA International Space Planes and Hypersonic Systems and Technologies Conference, p. 2350. (2011). https://doi.org/10.2514/6.2011-2350

[8] Hohn, Oliver, and Ali Gülhan. "Experimental investigation on the influence of yaw angle on the inlet performance at Mach 7." In 48th AIAA Aerospace Sciences Meeting Including the New Horizons Forum and Aerospace Exposition, p. 938. (2010). https://doi.org/10.2514/6.2010-938

[9] Tan, H. J., S. Sun, and H. X. Huang. "Behavior of shock trains in a hypersonic inlet/isolator model with complex background waves." Experiments in fluids 53, no. 6 (2012): 1647-1661. https://doi.org/10.1007/s00348-012-1386$\underline{1}$

[10] Idris, Azam Che, Mohd Rashdan Saad, Hossein Zare-Behtash, and Konstantinos Kontis. "Luminescent measurement systems for the investigation of a scramjet inlet-isolator." Sensors 14, no. 4 (2014): 6606-6632. https://doi.org/10.3390/s140406606

[11] Idris, Azam Che, Mohd Rashdan Saad, Kin Hing Lo, and Konstantinos Kontis. "Background-oriented schlieren (BOS) for scramjet inlet-isolator investigation." In IOP conference series: materials science and engineering, vol. 370 . IOP Publishing, 2018. https://doi.org/10.1088/1757-899X/370/1/012003

[12] Idris, Azam Che, Mohd Rashdan Saad, Mohd Rosdzimin Abdul Rahman, F. R. Hashim, and K. Kontis. "Experimental validation of artificial neural network (ANN) model for scramjet inlet monitoring and control." Int J Recent Technol Eng 7, no. 5 S4 (2019): 558-563.

[13] Saad, Mohd R., Hossein Zare-Behtash, Azam Che-Idris, and Konstantinos Kontis. "Micro-ramps for hypersonic flow control." Micromachines 3, no. 2 (2012): 364-378. https://doi.org/10.3390/mi3020364

[14] Saad, Mohd Rashdan, A. Idris, H. Zare-Behtash, and Konstantinos Kontis. "Micro-ramps in Mach 5 hypersonic flow." In 50th AIAA aerospace sciences meeting including the new horizons forum and aerospace exposition (2012): 676. https://doi.org/10.2514/6.2012-676

[15] Sidhu, Baljit Singh, Mohd Rashdan Saad, Ku Zarina Ku Ahmad, and Azam Che Idris. "Riblets for airfoil drag reduction in subsonic flow." ARPN J Eng Appl Sci 11, no. 12 (2016): 7694-7698.

[16] Idris, A. C., M. R. Saad, and K. Kontis. "Microvortex generator for scramjet inlet application." Progress in Propulsion Physics-Volume 1111 (2019): 747-758. https://doi.org/10.1051/eucass/201911747

[17] McCormick, D. C. "Shock/boundary-layer interaction control with vortex generators and passive cavity." AIAA journal 31, no. 1 (1993): 91-96. https://doi.org/10.2514/3.11323

[18] Babinsky, H., YI Li, and CW Pitt Ford. "Microramp control of supersonic oblique shock-wave/boundary-layer interactions." AIAA journal 47, no. 3 (2009): 668-675. https://doi.org/10.2514/1.38022

[19] Anderson, Bernhard, Jon Tinapple, and Lewis Surber. "Optimal control of shock wave turbulent boundary layer interactions using micro-array actuation." In 3rd AIAA flow control conference (2006): 3197. https://doi.org/10.2514/6.2006-3197

[20] Blinde, Paul L., Ray A. Humble, Bas W. Van Oudheusden, and Fulvio Scarano. "Effects of micro-ramps on a shock wave/turbulent boundary layer interaction." Shock Waves 19, no. 6 (2009): 507. https://doi.org/10.1007/s00193$\underline{009-0231-9}$ 
[21] Zhu, Yangzhu, Shihe Yi, Haolin Ding, Wansheng Nie, and Zhongwei Zhang. "Structures and aero-optical effects of supersonic flow over a backward facing step with vortex generators." European Journal of Mechanics-B/Fluids 74 (2019): 302-311. https://doi.org/10.1016/i.euromechflu.2018.09.003

[22] Qinghu, Zhang, Xu Xiaobin, Wang Xiong, Lin Jingzhou, and Tong Hua. "Effect of micro-ramps on supersonic boundary layer past a double wedge." Journal of Visualization 21, no. 1 (2018): 1-4. https://doi.org/10.1007/s12650-017-0441-7

[23] Kaushik, Mrinal. "Experimental studies on micro-vortex generator controlled shock/boundary-layer interactions in mach 2.2 intake." International Journal of Aeronautical and Space Sciences 20, no. 3 (2019): 584-595. https://doi.org/10.1007/s42405-019-00166-5

[24] Verma, S. B., and C. Manisankar. "Control of a Mach reflection-induced interaction using an array of vane-type vortex generators." Shock Waves 28, no. 4 (2018): 815-828. https://doi.org/10.1007/s00193-017-0780-2

[25] Rahman, Mohd Rosdzimin Abdul, Kin Yuen Leong, Azam Che Idris, Mohd Rashdan Saad, and Mahmood Anwar. "Numerical analysis of the forced convective heat transfer on Al $203-\mathrm{Cu} /$ water hybrid nanofluid." Heat and Mass Transfer 53, no. 5 (2017): 1835-1842. https://doi.org/10.1007/s00231-016-1941-z

[26] Rahman, Mohd Rosdzimin Abdul, Kin Yuen Leong, Azam Che Idris, and Mohd Rashdan Saad. "Thermal fluid dynamics of Al2O3-Cu/water hybrid nanofluid in inclined lid driven cavity." Journal of Nanofluids 6, no. 1 (2017): 149-154. https://doi.org/10.1166/jon.2017.1300

[27] Shuib, W. M. A. W., Azam Che Idris, Mohd Rashdan Saad, Mohd Faizal Hasan, and M. R. Rahman. "Study on the effect of bluff body with slit in the micro-channel combustor." J Adv Res Fluid Mech Thermal Sci 52, no. 2 (2018): 215-222.

[28] Abd Majid, Nurulhasnan, Azam Che Idris, Hasan Mohd Faizal, Mohd Rosdzimin Abdul Rahman, and Seyed Ehsan Hosseini. "Characteristics of liquid fuel combustion in a novel miniature vortex combustor." Journal of Thermal Analysis and Calorimetry (2019): 1-10. https://doi.org/10.1007/s10973-019-09011-z

[29] Slater, John W., and John D. Saunders. "Computational fluid dynamics (CFD) simulation of hypersonic turbine-based combined-cycle (TBCC) inlet mode transition." (2010).

[30] Nguyen, Tue, Gero Schieffer, Christian Fischer, Herbert Olivier, Marek Behr, and Birgit Reinartz. "Details of turbulence modeling in numerical simulations of scramjet intake." In 27th Congress of International Council of the Aeronautical Sciences (ICAS), Nice, France (2010): 19-24.

[31] Erdem, E., K. Kontis, and L. Yang. "Steady energy deposition at Mach 5 for drag reduction." Shock Waves 23, no. 4 (2013): 285-298. https://doi.org/10.1007/s00193-010-0247-1

[32] Guan, Xiang Yi. "Verification of FLUENT in the Computation of Supersonic Inlet." In Advanced Materials Research, vol. 591, Trans Tech Publications Ltd, (2012): 2064-2067. https://doi.org/10.4028/www.scientific.net/AMR.591$\underline{593.2064}$

[33] Reinartz, Birgit. "Parameter Study for Scramjet Intake Concerning Wall Temperatures and Turbulence Modeling." In High Performance Computing in Science and Engineering'11 (2012): 425-436. https://doi.org/10.1007/978-3642-23869-7 31 